\title{
VASCULAR ENDOTHELIAL GROWTH FACTOR AND INSULIN LIKE GROWTH FACTOR-1 LEVELS IN PREMATURES SERUM, ITS RELATION TO THE DEVELOPMENT OF RETINOPATHY OF PREMATURITY
}

\author{
E.R. Abdel Hameed ${ }^{1}$, I. Othman ${ }^{2}$, R. Sabry ${ }^{1}$, G. Sidhom ${ }^{3}$, R. Mahmoud ${ }^{4}$, A. Gabre ${ }^{1}$ \\ ${ }^{1}$ Child Health Department, National Research Center, El Giza, ${ }^{2}$ Department of Ophthalmology, Cairo \\ University, Cairo, ${ }^{3}$ Clinical Pathology Department, National Research Center, El Giza, ${ }^{4}$ Department of \\ Medical Studies, Institute of Postgraduate Childhood Studies, Cairo, Egypt
}

Background: Survival of premature infants in Egypt has increased due to advances in antenatal and neonatal care. This has resulted in a population of infants at high risk of developing Retinopathy of Prematurity.

Objective: To evaluate the role of cytokines (IGF-1 and VEGF) in serum of premature infants as possible diagnostic markers for ROP.

Methods: Eighty three premature neonates were admitted to the NICU of Almaza charity neonatal care unit in Cairo were included in this study. They were classified into two groups: those developing ROP $(\mathrm{n}=34)$ and those without ROP $(\mathrm{n}=49)$. The ROP group was subdivided to: mild cases (stages I and II ROP) and severe cases( stages III and V ROP).We obtained serum from each infant at 4 to 6 weeks postnatal weeks for estimation of IGF-1 and VEGF level.

Results: There were significant differences in the amount of the cytokines IGF-1 and VEGF between the groups with and without ROP, but there were no significant differences between mild and severe ROP regarding the serum levels of cytokines. Univariate statistical analysis revealed that low IGF-1 and high VEGF serum levels can be useful as indicators in ROP screening but multivariate logistic regression analysis showed that only elevated VEGF serum level helps to predict the probability of suffering from the illness.

Conclusions: At 4 weeks postnatal age, VEGF and IGF-1 serum levels in premature infants can be useful as an indicator in ROP screening. Serum VEGF helps to predict the probability of suffering from the illness. 